Outcomes review

\title{
Pramipexole in restless legs syndrome: an evidence-based review of its effectiveness on clinical outcomes
}

\author{
William Winlow
}

Core Medical Publishing, Knutsford, UK

\begin{abstract}
Introduction: Restless legs syndrome (RLS) affects $5-15 \%$ of adults, but is often unrecognized and consequently misdiagnosed. The International Restless Legs Scale (IRLS) has been developed and validated to assess the severity of RLS. Currently, the most common treatment for RLS is levodopa, but this may lead to augmentation of symptoms. Pramipexole has been developed as an alternative treatment for patients diagnosed with RLS.
\end{abstract}

Aims: The objective of this article is to review the evidence of the effectiveness of pramipexole for the clinical management of patients with RLS.

Evidence review: There is clear evidence that pramipexole reduces the leg movements associated with RLS, as measured by improvements in both the IRLS and the Clinical Global Impression (CGI) score. There is also moderate evidence that the drug improves sleep quality. Pramipexole clearly improves the anxiety and depression often associated with RLS. Augmentation may be associated with pramipexole treatment, but the evidence is contradictory and augmentation may be more associated with patients pretreated with levodopa or with patients with primary RLS rather than those with secondary RLS. Pramipexole therapy appears to be well tolerated, with only mildto-moderate adverse events reported.

Outcomes summary: Pramipexole reduces leg movements in RLS, and is well tolerated. Further investigation is required to confirm the preliminary evidence that pramipexole restores normal sleep architecture and restores a normal quality of life in patients with RLS. Health economic studies would be valuable in demonstrating the true impact of pramipexole on the social burden of RLS.

Key words: restless legs syndrome (RLS), pramipexole, outcomes, evidence

\section{Core evidence outcomes summary for pramipexole in restless legs syndrome}

\begin{tabular}{|c|c|c|}
\hline Outcome measure & Evidence & Implications \\
\hline \multicolumn{3}{|l|}{ Patient-oriented evidence } \\
\hline Significant reduction in leg movements during sleep & Clear & Pramipexole is effective \\
\hline No serious adverse events during $3-6$ weeks of therapy & Clear & Well tolerated in short-term treatment \\
\hline Low-dose pramipexole improves sleep indices & Clear & $\begin{array}{l}\text { Improves sleep, but questions arise over sleep efficiency and sleep } \\
\text { architecture }\end{array}$ \\
\hline Low-dose pramipexole improves depression in patients with RLS & Clear & Pramipexole reduces both sensorimotor and depressive symptoms \\
\hline No serious adverse events over prolonged periods up to 2 years & Moderate & May be well tolerated as long-term treatment by the majority of patients \\
\hline $\begin{array}{l}\text { Pramipexole does not cause augmentation over periods in } \\
\text { excess of } 2 \text { years }\end{array}$ & Moderate & $\begin{array}{l}\text { Evidence is divided on the extent of augmentation and whether or not } \\
\text { it varies in different patient groups }\end{array}$ \\
\hline
\end{tabular}




\section{Scope, aims, and objectives}

To review the evidence of the effectiveness of pramipexole (Boehringer Ingelheim) on outcomes and potential for clinical management of patients with restless legs syndrome (RLS).

\section{Methods}

Searches of the English language medical literature were conducted between December 14 and 21, 2004, on January 17, 2005, and on March 15, 2005 on the following databases:

- PubMed, www.ncbi.nlm.nih.gov/entrez, 1966 to date

- Database of Abstracts of Reviews of Effectiveness (DARE), NHS Economic Evaluations Database (NHSEED), Health Technology Assessment (HTA), www.york.ac.uk/inst/crd/darehp.htm

- NHS HTA, www.ncchta.org

- National Guidelines Clearinghouse, www.guideline.gov

- Cochrane Database of Systematic Reviews, www.cochrane.org

- Clinical Evidence, www.clinicalevidence.com

The results of the searches are summarized in Table 1. Review articles, letters, and articles not directly linked to RLS were excluded from analysis (see Editorial Information on inside back cover).

Search terms used were: pramipexole and restless legs syndrome; Mirapex and restless legs syndrome; restless legs syndrome; restless legs syndrome and cost; review and methodology studies; pramipexole, restless legs and randomized controlled trials; Mirapex, restless legs and randomized controlled trials.

\section{Disease overview}

\section{Characteristics of RLS}

RLS or Ekbom's syndrome (Ekbom 1945) is a sensory motor disorder characterized by a compelling urge to move the limbs

\section{Table 1 | Evidence base included in the review}

\begin{tabular}{|lcc|}
\hline & \multicolumn{2}{c|}{ Number of records } \\
\cline { 2 - 3 } Category & Full papers & Abstracts \\
\hline Initial search & 31 & 0 \\
records excluded & 21 & \\
records included & 10 & \\
Additional studies identified & 1 & 6 \\
Level 1 clinical evidence & 0 & 0 \\
Level 2 clinical evidence & 1 & 6 \\
Level $\geq 3$ clinical evidence & 10 & 0 \\
trials other than RCT & 10 & 0 \\
case reports & 0 & 0 \\
Economic evidence & 0 & 0 \\
\hline RCT, randomized controlled trials. & & \\
\hline
\end{tabular}

(Thorpy et al. 2000), which is diagnosed on the basis of the patient's symptoms and history (Thorpy et al. 2000; Allen et al. 2003). It may be accompanied by unpleasant creeping or twitching sensations in the affected limbs and is often associated with paresthesias and dysthesias (Chaudhuri et al. 2004). RLS is a progressive disease with intermittent and fluctuating symptoms at the beginning, which increase in severity over time (Allen et al. 2003).

The symptoms associated with RLS often intensify at rest, particularly in the evening or at night, resulting in sleep disturbances and insomnia (Lesage \& Hening 2004; Silber et al. 2004). Patients are often unable to tolerate sedentary activities and are prone to daytime sleepiness and general fatigue as well as impaired cognitive function; some also experience pain in the affected limbs. RLS may also give rise to anxiety, depression, and a reduced quality of life (QOL) (Lesage \& Hening 2004). According to Thorpy et al. (2000), sleep disruption combined with difficulties in tolerating sedentary activities can compromise an individual's lifestyle, perhaps leading to job loss and problems with relationships. Overall, the symptoms associated with RLS can result in patients being severely incapacitated, possibly leading to serious socioeconomic effects for them, although no health economic evaluations have been reported. Any new treatment for RLS should therefore address the mood disorders associated with RLS as well as the primary problem of restless legs.

\section{Prevalence and etiology of RLS}

Several studies suggest that $5-15 \%$ of the adult population is affected by RLS, but that only those with moderate-to-severe symptoms, perhaps $3 \%$ of adults, seek medical treatment (Chaudhuri et al. 2004; Lesage \& Hening 2004; Silber et al. 2004; Thorpy et al. 2000). RLS has a variable age of onset, and can occur in children, but its prevalence increases with age; women are also more likely to develop RLS than men (Chaudhuri et al. 2004). Up to $40 \%$ of patients with severe RLS experienced their first symptom before the age of 20 years. The condition may be exacerbated by stress and psychiatric conditions. RLS can be classified as primary or secondary, both having similar symptoms. Primary RLS appears to be of genetic origin, with a positive family history in $60 \%$ of cases (Thorpy et al. 2000). According to Chaudhuri et al. (2004), secondary RLS has a faster rate of progression than primary RLS and may be associated with a number of conditions including: central iron deficiency (sometimes without significant anemia), neurologic lesions of the spinal cord and peripheral nerves, pregnancy, and end-stage renal disease. Recently, it has been reported that there is a bilateral increase in the gray matter of the pulvinar nucleus of the thalamus in patients with idiopathic RLS, but it is not known if this is involved in the pathogenesis of RLS or is a consequence of an increase in afferent input due to RLS (Etgen et al. 2005).

\section{Pathophysiology of RLS}

There is substantial evidence to support the central role of dopaminergic systems in the pathophysiology of RLS; for example a mild reduction in dopamine levels has been observed in the nigrostriatal pathway in patients with periodic limb movement disorder (PLMD) and RLS (Ruottinen et al. 2000). This is supported by the fact that RLS may be induced or worsened by a number of drugs including tricyclic antidepressants (probably acting 
Table 2 | Essential diagnostic criteria for restless legs syndrome. Based on Allen et al. (2003), Chaudhuri et al. (2004), and Thorpy et al. (2000)

\begin{tabular}{|c|c|}
\hline Criteria & Description \\
\hline Criterion 1 & $\begin{array}{l}\text { A compelling urge to move the legs, usually accompanied or caused by uncomfortable (paresthesias) and unpleasant (dysesthesias) } \\
\text { sensations in the legs-sometimes the urge to move occurs without the unpleasant sensations and sometimes the arms or other body } \\
\text { parts are involved in addition to the legs }\end{array}$ \\
\hline Criterion 2 & The urge to move or unpleasant sensations begin or worsen during periods of rest or inactivity such as lying or sitting \\
\hline Criterion 3 & Symptoms are partially or totally relieved by movement, such as walking or stretching, at least as long as the activity continues \\
\hline Criterion 4 & Symptoms are worse in the evening and at night \\
\hline
\end{tabular}

nonspecifically to block uptake of amines by nerve terminals), selective serotonin reuptake inhibitors (SSRIs) [probably due to dopamine-dependent side effects of SSRIs (Damsa et al. 2004)], and dopamine antagonists (Thorpy et al. 2000). This indicates that dysfunction of central dopaminergic systems of neurons may be implicated in the pathophysiology of RLS. However, StiasnyKolster et al. (2004b) indicate that imaging studies and analysis of dopamine metabolites do not provide evidence for either a dopaminergic deficit or neurodegeneration in the basal ganglia.

Levodopa and dopamine agonists are known to be efficacious in RLS (Akpinar 1982), while dopamine antagonists worsen the syndrome. Furthermore, dopamine levels have a known circadian rhythmicity and RLS symptoms coincide with lower central dopamine levels (Sowers \& Vlachakis 1984). However, this could imply a functional impairment of the dopaminergic system or a modulating influence on it, since melatonin inhibits central dopamine secretion during daytime and is itself increased at night (Stiasny-Kolster et al. 2004b).

Tyrosine hydroxylase, the rate-limiting enzyme for the synthesis of dopamine, requires iron as a cofactor, and it has been suggested that lack of iron availability in the central nervous system (CNS) affects dopamine metabolism (Happe \& Trenkwalder 2004). In patients with RLS, there is reduced staining for ferritin receptors in the substantia nigra, perhaps due to an inadequate increase in iron regulatory proteins that induce ferritin-receptor synthesis (Earley et al. 2000). Furthermore, Kotagal and Silber (2004) have recently demonstrated that iron deficiency and a positive family history are characteristic of childhood-onset RLS. These findings clearly indicate that brain iron depletion may be one cause of abnormally low dopamine levels, which have a central role in the pathophysiology of RLS. Alternatively, these effects could be due to compromised iron acquisition in neuromelanin cells, which may disrupt dopaminergic mechanisms (Stiasny-Kolster et al. 2004c).

Recent studies suggest that RLS may, in part, be a pain disorder (Stiasny-Kolster et al. 2004c). In patients with RLS it has been shown that there is profound hyperalgesia to punctate stimuli, which may be improved by dopaminergic drugs. This may be due to abnormal sensory input and/or altered descending inhibition from the supraspinal dopaminergic system.

\section{Underrecognition and misdiagnosis of RLS}

Because RLS is not well known and frequently unrecognized, it is often misdiagnosed-only about $13 \%$ of patients presenting to primary care physicians (PCPs) are accurately diagnosed (Chaudhuri et al. 2004)-patients often receive either no treatment or drugs to alleviate the sleep disorder rather than the underlying condition.

PLMD, or nocturnal myoclonus, is distinguishable from RLS, but is often associated with it in the form of periodic limb movements of sleep (PLMS) (Lesage \& Hening 2004). PLMS can occur in healthy individuals and in patients with a range of disorders and is not always associated with RLS (Montplaisir et al. 1997). Furthermore, PLMD is polysomnographically distinct from RLS with more spontaneous electroencephalogram (EEG) arousals occurring in RLS than PLMD (Eisenehr et al. 2003).

Neither RLS nor PLMS should be confused with akathisia (inability to sit or stand still) in which patients complain of restlessness accompanied by movements such as fidgeting of the legs, rocking from foot to foot, pacing, or inability to sit or stand. Although akathisia can occur spontaneously, it is most commonly observed as a side effect of antipsychotic medications (neuroleptics) (Barnes 1987) and has no circadian rhythmicity (Walters et al. 1991).

A multinational questionnaire survey of more than 23000 subjects and their PCPs $(n=182)$ highlighted the extent of the underrecognition of RLS, in which almost $10 \%$ of subjects reported weekly RLS symptoms (Hening et al. 2004b). Bias was reduced in the survey since neither the PCPs nor the patients were made aware of the subject of the investigation until after they had agreed to participate. A sufferer subgroup of 551 patients who warranted treatment for RLS was identified on the basis of at least twice-weekly symptoms with appreciable negative impact on QOL. Of the subgroup, 357 (65\%) reported that they had consulted a physician, and only 46 of these 357 (13\%) reported being diagnosed with RLS. PCPs reported that 209 (38\%) of RLS patients consulted them about associated symptoms, but only $52(25 \%)$ had been given a diagnosis of RLS.

In most countries regardless of diagnosis, the majority of RLS patients were prescribed therapies inappropriate for the treatment of RLS. These data highlight the need to increase awareness among both patients and physicians of how RLS presents, to make physicians more aware of how it is diagnosed and the medications that are most effective for its treatment.

\section{Assessment and diagnosis of RLS}

In 2003 the International RLS Study Group (IRLSSG) established four criteria by which RLS can be easily recognized by the PCP (Table 2). They also developed additional criteria for the diagnosis 
of RLS in cognitively impaired elderly and in children. Several rating scales and objective tests have also been developed to determine the severity of RLS. The International Restless Legs Scale (IRLS, occasionally known as the RLS Rating Scale or RLSRS), developed and validated by the IRLSSG (2003), consists of 10 items each rated on a 5-point severity scale. In a small study of 30 patients the IRLS was shown to correlate significantly with other objective measures of RLS such as various measures of motor dysfunction in sleep/wakefulness during polysomnography (PSG) the Suggested Immobilization Test (SIT), the Periodic Leg Movement of Sleep index (PLMS-index), the PLMS-arousal index during PSG, and the Periodic Leg Movement of Wakefulness (PLMW) during SIT (SITPLMW) (Garcia-Borreguero et al. 2004).

Most cases of RLS can be diagnosed by taking a thorough clinical history and conducting a physical examination to rule out other disorders, particularly neurologic and vascular disorders, and to identify secondary causes (Thorpy et al. 2000). Laboratory tests may then reveal other possible secondary causes such as uremia or low ferritin levels $(<50 \mathrm{mcg} / \mathrm{L})$. It is not routine to refer patients for a sleep study since it should be possible to diagnose RLS on the basis of the patient's history and additional clinical findings. However, if PSG is thought necessary it will involve monitoring a number of physiologic variables during sleep, including brain electrical activity using an EEG; eye movements by electroocculography; jaw and leg muscle activity/movement by electromyography; heart activity by electrocardiography; airflow using a nasal thermistor; respiratory effort using piezo crystal transducers attached to bands around the chest and abdomen; and oxygen saturation using a pulse oximeter. These are research methods that are being used to help with the differential diagnosis of RLS from other related disorders.

\section{Current therapy options}

Various advisory guidelines and algorithms for the management of RLS are currently available (Thorpy et al. 2000; Lesage \& Hening 2004; Schapira 2004; Silber et al. 2004). However, there is no widely approved agent available for the treatment of RLS. Treatment varies according to RLS severity, for example dopaminergic agents such as levodopa or a dopamine agonist may be used in patients with intermittent RLS, while patients with severe symptoms may require strong opioids (Thorpy et al. 2000). However, treatment of RLS has typically involved the use of benzodiazepines, which are anxiolytic and hypnotic agents, and other sedative drugs that may provide symptomatic relief but do not influence the course of RLS.

Recently, dopaminergic agents have emerged as the treatment of choice for RLS (e.g. Happe \& Trenkwalder 2004). Among these, the dopamine precursor levodopa is the only drug currently indicated for RLS, but only in Germany, Austria, and Switzerland. Although the efficacy of levodopa has been established, it is associated with a high incidence of long-term adverse effects including augmentation, whereby the symptoms of RLS are worsened by the therapy, and increasing quantities of medication are required, often earlier in the day. In vitro experiments with levodopa, which is a dopamine precursor, suggested that it was toxic to dopamine neurons, but this is not supported by in vivo studies (Ferraro et al. 2003; Mytilineou et al. 2003).
Accumulating data suggest that the dopamine agonists may provide alternative therapy, with substantially lower augmentation rates than levodopa (Lesage \& Hening 2004). Furthermore, it has been suggested that $D_{3}$ dopamine receptor agonists have neuroprotective effects since they increase the production of dopamine neurotrophic factor in tissue culture (Carvey et al. 2001), although this has recently been questioned (Clarke 2004).

The nonergot $D_{3}$ autoreceptor agonist pramipexole, which is indicated for the treatment of Parkinson's disease, is currently being evaluated for RLS in phase III trials. Other dopamine agonists which are currently being evaluated for RLS include the $D_{2}$ agonists ropinirole, which has recently been approved by the FDA (Anon. 2005) and rotigotine which is being investigated in a transdermal patch delivery system in phase II studies. Recent trials on cabergoline (Stiasny-Kolster et al. 2004d) and pergolide (Trenkwalder et al. 2004) have also been reported. The dopaminergic treatment of RLS and PLMD has recently been reviewed (Hening et al 2004a).

No comparative data on the relative efficacy, tolerability, and safety of the dopamine agonists have yet been reported. However, evidence is accumulating to show that different groups of dopamine receptors may be functionally compartmentalized in the brain (Black et al. 2002), and it has been suggested that $D_{3}$ receptors in the mesolimbic system may have a specific role to play in the pathophysiology of RLS (Montplaisir et al. 2000).

In addition to its affinity for $D_{3}$ receptors, pramipexole is also a potent $D_{2}$ agonist (Black et al. 2002), which is why it is effective in the treatment of movement disorders such as Parkinson's disease, and has the potential to be beneficial in the management of RLS (Strange 2000). However, pramipexole has even higher affinity for $D_{3}$ receptors (5-10-fold more than $D_{2}$ receptors), which means that it may also have effects on mood via these receptors. When compared with other $D_{2}$-like receptors, $D_{3}$ receptors are differentially distributed in the mesolimbic/mesocortical system and prefrontal cortex (Black et al. 2002), which is closely linked to the emotional part of the brain, the limbic system, thereby playing a role in control of mood. Thus pramipexole may have the clinical potential to modify both the limb movements and mood changes associated with RLS.

\section{Unmet needs}

Even in the small proportion of diagnosed cases of RLS, patients are often only given symptomatic treatments, none of which treat the underlying problem of RLS (Hening et al. 2004b). The only drug currently licensed for RLS is levodopa. However, it is associated with potential long-term adverse events, particularly those associated with augmentation, for example involuntary movements, nausea, vomiting, and postural hypotension. These adverse effects limit the use of levodopa and are often worse than the symptoms of RLS. An ideal drug for RLS would not only suppress RLS symptoms, stop PLMs, but would also restore natural sleep, diminish the depression and anxiety associated with RLS, and delay the progression of the disease. New drugs that avoid the consequences of the prolonged use of levodopa are therefore required for the treatment of RLS, which is why the dopamine agonists, such as pramipexole, are being evaluated for the treatment of RLS. 


\section{Clinical evidence from pramipexole in RLS}

\section{Leg movements}

In early studies with pramipexole there was a reduction of the mean ILRS score from 17 (SD 4.3) to 7.8 (SD 4.9) $(P<0.0001)$ in a two-centre, open-label, questionnaire-based study on 23 patients with RLS (Becker et al. 1998). After at least 4 weeks of treatment with pramipexole, 19 patients reported improvement as assessed by their RLSRS scores. In another small open-label study of 16 patients both nocturnal leg restlessness and nocturnal involuntary leg movements were analyzed using a visual analog scale (VAS). Although the data obtained were subjective, after 2-3 months' treatment most patients reported improvements in both these areas (Lin et al. 1998). A more recent, retrospective study of 60 patients showed that pramipexole was effective in controlling RLS in $67 \%$ of patients, partially effective in $27 \%$, and ineffective in $7 \%$ (Silber et al. 2003). In a short-term openlabel PSG on 17 patients, insufficiently treated with levodopa, a single low dose $(0.125-0.75 \mathrm{mg}$, mean $0.3 \pm 0.2 \mathrm{mg})$ of pramipexole in the evening resulted in an improvement of their symptoms when rated on the IRLS and was well tolerated (Stiasny-Kolster \& Oertel 2004). PSG recordings showed that patients experienced improvements in the Periodic Limb Movement Index (PLMI) and PLMS as well as sleeponset latency, total sleep time, and sleep efficiency.

Only three randomized controlled trials (RCTs) of pramipexole in RLS have so far been reported [Montplaisir 1999; Partinen et al. 2004 (see also Prescott 2004); Högl \& Poewe 2005a/Oertel \& StiasnyKolster 2005a,b]. In a 10-week, double-blind RCT Montplaisir (1999) demonstrated that pramipexole reduced the PLMS-index to normal values in a study of 10 patients. PLMW was also significantly reduced $(P=0.007)$. These results were supported by a study on 109 patients with idiopathic RLS who were enrolled into a double-blind, single-center RCT, using comprehensive PSG techniques (Partinen et al. 2004). The primary endpoint of the study was a reduction in limb movements as assessed by the PLMI during time in bed. Pramipexole showed excellent efficacy across the tested dose range of $0.125-0.75 \mathrm{mg} /$ day within 3 weeks of therapy and there was a statistically significant reduction in the PLMI versus placebo $(P<0.0001)$. Clinical efficacy was greatest in patients receiving 0.5 and $0.75 \mathrm{mg}$ pramipexole per day. With $0.125 \mathrm{mg}$ pramipexole the IRLS score was reduced by $60 \%$, by $78 \%$ with $0.5 \mathrm{mg}$ and $75 \%$ with $0.75 \mathrm{mg}$ as compared with placebo $(P<0.0001)$.

These data were reflected in the patients' reported outcomes, using CGI scores, $60 \%$ of whom reported "much" to "very much" improvement with $0.125 \mathrm{mg}$ pramipexole, up to $85 \%$ with $0.5 \mathrm{mg}$ and $83 \%$ with $0.75 \mathrm{mg}$. A further study in 345 patients with idiopathic RLS showed that pramipexole significantly $(P<0.0001)$ improved symptoms when measured on a CGI scale and a VAS over a 6-week period (Oertel \& Stiasny-Kolster 2005a). Pramipexole produced a significant $(P<0.0001)$ benefit after only 1 week of treatment when measured by patient global improvement (PGI) ratings and at the end of 6 weeks significantly $(P<0.0004)$ more patients in the pramipexole group experienced an improvement in symptoms when compared with the placebo group (Oertel \& Stiasny-Kolster 2005b). Furthermore, Högl and Poewe (2005a) have shown, in a substudy, that a single dose of pramipexole $(0.125-0.75 \mathrm{mg})$ per day significantly $(P<0.0001)$ reduced the severity of daytime and nighttime RLS over the course of $24 \mathrm{~h}$.

\section{Sleep quality}

There is some evidence that the effect of pramipexole in reducing leg movements has a benefit to patients in terms of improved sleep quality.

In a small open-label trial on 16 patients in a sleep disorder center, insomnia was analyzed using a VAS. Although the data obtained were subjective, after 2-3 months the majority of patients (11 of 16) reported clinically significant improvements in insomnia (Lin et al. 1998). This is supported by a PSG study that demonstrated moderately improved sleep quality, although there were some changes in sleep architecture (Saletu et al. 2002). Furthermore, Högl and Poewe (2005b) showed, in an RCT on 345 patients with RLS, that a single dose $(0.175-0.75 \mathrm{mg})$ of pramipexole over a 24-h period significantly improved sleep compared with placebo $(P=0.0001)$ over a 6 -week period. A retrospective study of 24 patients with RLS also indicated that pramipexole $(0.125-0.75 \mathrm{mg})$ did not increase the risk of daytime sleep episodes (StiasnyKolster et al. 2000).

Further studies on sleep-onset latency, sleep quality, sleep efficiency, and sleep architecture would be welcome to confirm that patients with RLS treated with pramipexole experience good quality sleep and do not have daytime fatigue after treatment, and to test whether different groups of patients respond differentially to treatment.

\section{Anxiety and depression}

Ideally, drugs used for the treatment of RLS should also address the associated anxiety and depression. There is clear evidence for pramipexole on this outcome. The PSG study on 11 patients with RLS by Saletu et al. (2002) indicated that after 4 weeks of pramipexole therapy $(0.28 \pm 0.1 \mathrm{mg})$, patient self-rating depression scores improved by $23 \%$. The study on 345 patients with RLS (Stiasny-Kolster \& Oertel 2005) indicated that pramipexole significantly $(P<0.0001)$ improved severe mood disturbances and depressive symptoms when compared with placebo.

Clinical trials will need to be carefully designed to clarify whether anxiety and depression are part of RLS or merely its sequelae. Studies on the effects of pramipexole on mood disturbances would also be useful to ascertain its impact on the full spectrum of consequences of RLS.

\section{Quality of life}

Clinical trials to determine the impact of pramipexole on QOL have not yet been reported. Such studies are important because undiagnosed or misdiagnosed RLS leads to a decline in QOL, as a result of physical discomfort, sleep disturbances, and fatigue.

\section{Adverse events and tolerability}

The occurrence of adverse events associated with pramipexole is not always fully described, but according to Silber et al. (2003) $40 \%$ of patients experienced mild side effects. The most common adverse events include mild nausea and daytime fatigue, insomnia, constipation, dyspepsia, loss of appetite, tachycardia, and dizziness (Becker et al. 1998; Comella 2002; Ferini-Strambi 2002; 
Silber et al. 2003), none of which occurred in more than $13 \%$ of patients. In the study by Partinen et al. (2004) safety and tolerability were reported to be favorable at all dose levels and no serious adverse events were reported in this or other reports (e.g. Oertel \& Stiasny-Kolster 2005a).

\section{Augmentation}

There is some evidence from observational studies on the incidence of augmentation with pramipexole in short- and longerterm treatment. A follow-up study on seven of the patients from the RCT conducted by Montplaisir et al. (1999) was carried out for a mean duration of 7.8 months using home questionnaires (Montplaisir et al. 2000). This indicated that there was no decrease in the therapeutic effect of pramipexole, although there was a progressive increase in the severity of leg movements before taking a single dose of pramipexole $(0.375-1.5 \mathrm{mg} /$ day) before bedtime. Similarly, Ferini-Strambi (2002) showed only an $8 \%$ augmentation rate in 60 patients over a 6-month period.

Longer-term studies indicate a higher rate of augmentation. In a retrospective study, augmentation developed in $43 \%$ of 83 patients over 39.2 months ( \pm 20.9 months) after treatment with pramipexole (52 patients), ropinirole (19 patients), or pergolide (12 patients) (Ondo et al. 2004). Efficacy was maintained by moderate increases in dose $(P<0.01)$ although absolute values were not reported. These data suggest that patients with secondary RLS are less likely to develop augmentation than those with primary RLS. However, these data must be treated with some reserve, since most of the patients were either not on monotherapy or altered their dopaminergic medication during their course of treatment.

Winkelman and Johnston (2004) reported a naturalistic case series for the effects of pramipexole. Fifty-nine patients met the inclusion criteria and were retrospectively analyzed after at least 6 months (mean $\pm S D=21.2 \pm 11.4$ months). Their findings showed that augmentation developed in $32 \%$ of patients and tolerance in $46 \%$ of patients. However, they also found that previous augmentation $(n=38)$ or tolerance $(n=34)$ with levodopa significantly increased the probability of both augmentation and tolerance to pramipexole.

In contrast, a study in 60 patients with RLS found that augmentation developed in $20 \%$ in the first year and $30 \%$ after 2 years, but that the risk of augmentation tapered off after 2.5 years of treatment with pramipexole, and augmentation did not appear to be associated with previous levodopa/carbidopa or pergolide treatment (Silber et al. 2003).

From these findings, it is clear that comparative studies on augmentation of RLS by pramipexole are required to determine its time course and its prevalence amongst different groups of patients.

\section{Resource utilization}

The economic effects of misdiagnosed or undiagnosed RLS have not yet been reported. However, given that $5-15 \%$ of the adult population is affected, the direct and indirect economic consequences of the disease are likely to be significant.
It can be predicted that earlier recognition of RLS, particularly by PCPs, would reduce the number of undiagnosed and misdiagnosed cases of RLS, with a consequent reduction in the misapplication of resources. The IRLS (IRLSSG 2003) provides PCPs with an adequate tool for the evaluation of the severity of RLS, which, if widely introduced, would reduce the social, economic, and therapeutic impacts of RLS. This is important from the standpoint of both patients and care providers. Studies on the pharmacoeconomics and QOL of treatment with pramipexole are needed to determine the impact of the drug on the burden of RLS.

\section{Patient group/population}

Studies to date suggest that pramipexole should be a first-line choice for all patients with RLS. However, pramipexole may be less effective in patients with primary RLS (Ondo et al. 2004) who have previously been treated with other dopaminergic substances since they may be more likely to develop augmentation of the disease (Winkelman \& Johnston 2004).

\section{Outcomes summary}

RLS is a relatively common condition, which is frequently misdiagnosed. Thus, there is a need for improved diagnosis in primary care so that it can be treated appropriately, rather than being considered as primarily a sleep disorder. Given the potential economic and social costs of RLS, its severity needs to be recognized at an early stage by PCPs, preferably using the IRLS, which is specifically designed for this purpose (IRLSSG 2003).

Once a correct diagnosis has been achieved, the only drug currently indicated for the treatment of RLS is levodopa, but this is associated with a high incidence of adverse events (e.g. augmentation), which significantly limit its use. Nevertheless, in those patients where it does have utility, new treatments need to demonstrate at least equivalent efficacy to levodopa in terms of symptom relief and improved QOL, coupled with better tolerability and less chance of augmentation. Furthermore, because of the relatively low acquisition cost of levodopa, the direct and indirect economic consequences of any therapeutic benefit of new alternatives need to be quantified to assess the true impact on RLS management.

There is clear evidence that pramipexole is effective in reducing the leg movements associated with RLS, the major outcome measure of the disease. From the patients' perspective there is clear evidence that it improves the quality of sleep. It is well tolerated in short-term treatment (up to 6 weeks) and there is some evidence that this tolerability profile is maintained in the longer term $(>2$ years' treatment). There is also clear evidence that it improves depressive symptoms associated with RLS.

It appears that pramipexole may substantially lower augmentation rates compared with levodopa. At present, the lack of direct evidence makes it difficult to evaluate the impact of pramipexole on the economic and QOL burden of RLS. However, if future studies confirm the effectiveness of pramipexole in the treatment of RLS (particularly on sleep outcomes), its favorable tolerability profile, and its effect on QOL, then the drug may offer QOL and economic benefits compared with levodopa. 
Future studies need to demonstrate that pramipexole restores normal sleep architecture, prevents anxiety and depression associated with RLS, and improves patient QOL. Health economic studies would also be welcome to show the true economic and social burden of RLS.

\section{References}

Akpinar S. Treatment of restless legs syndrome with levodopa plus benserazide. Arch Neurol. 1982;39:739.

Allen RP, Picchietti D, Hening WA, et al. Restless legs syndrome: diagnostic criteria, special considerations and epidemiology. A report from the restless legs syndrome diagnosis and epidemiology workshop at the National Institutes of Health. Sleep Med. 2003;4:101-119.

Barnes TRE. The present status of tardive dyskinesia and akathesia in the treatment of schizophrenia. Psychiatr Dev. 1987;4:301-319.

Becker PM, Ondo, W, Sharon D. Encouraging initial response of restless legs syndrome to pramipexole. Neurology. 1998;51:1221-1223.

Black KJ, Hershey T, Koller JM, et al. A possible substrate for dopamine-related changes in mood and behaviour: prefrontal and limbic effects of a D3-preferring dopamine agonist. Proc Natl Acad Sci. 2002;99:17113-17118.

Carvey PM, McGuire SO, Ling ZD. Neuroprotective effects of D3 dopamine receptor agonists. Parkinsonism Relat Dis. 2001;7:213-223.

Chaudhuri KR, Forbes A, Grosset D, et al. Diagnosing restless legs syndrome (RLS) in primary care. Curr Med Res Opin. 2004;20:1785-1795.

Clarke E. Neuroprotection and pharmacotherapy for motor symptoms in Parkinson's disease. Lancet Neurol. 2004;3:466-474.

Comella CL. Restless legs syndrome: treatment with dopaminergic agents. Neurology. 2002;58(Suppl.1):S87-S92.

Damsa C, Bumb A, Bianchi-Demicelli F, et al. "Dopamine-dependent" side effects of selective serotonin reuptake inhibitors: a clinical review. J Clin Psychiatr. 2004;65:1064-1068.

Earley CJ, Connor JR, Beard JL, et al. Abnormalities in CSF concentrations of ferritin in restless legs syndrome. Neurology. 2000;54:1698-1700.

Eisenehr I, Ehrenberg BL, Noachtar S. Different sleep characteristics in restless legs syndrome and periodic movement disorder. Sleep Med. 2003;4:147-152.

Ekbom KA. Restless legs: a clinical study. Acta Med Scand.

1945;158(Suppl.):1-123.

Etgen T, Draganski B, llg C, et al. Bilateral thalamic gray matter changes in patients with restless legs syndrome. Neuroimage. 2005;24:1242-1247.

Ferraro JE, Delfino MA, Stefano AV, et al. Effects of orally administered levodopa on mesencephalic dopaminergic neurons undergoing a degenerative process. Neurosci Res. 2003;47:431-436.

Ferini-Strambi L. Restless legs syndrome augmentation and pramipexole treatment. Sleep Med. 2002;3:S23-S25.

Garcia-Borreguero D, Larrosa O, de la Llave Y, Granizo JJ, Allen R. Correlation between rating scales and sleep laboratory measurements in restless legs syndrome. Sleep Med. 2004;5:561-565.

Happe S, Trenkwalder C. Role of dopamine receptor agonists in the treatment of restless legs syndrome. CNS Drugs. 2004;18:27-36.

Hening W, Allen RP, Earley CJ, Picchietti DL, Silber MH, An update on the treatment of restless legs syndrome and periodic limb movement disorder. Sleep. 2004a;27:560-583.

Hening W, Walters AS, Allen RP, Montplaisir J, Myers A, Ferini-Strambi L. Impact, diagnosis and treatment of restless legs syndrome (RLS) in a primary care population: the REST (RLS epidemiology, symptoms, and treatment) primary care study. Sleep Med. 2004b;5:237-246.

Högl B, Poewe W. 24h-relief of restless leg syndrome (RLS) symptoms with once daily pramipexole. Mov Disord. 2005a;20(Suppl.10):S58, P193.

Högl B, Poewe W. Pramipexole significantly improves sleep in patients with restless leg syndrome (RLS). Mov Disord. 2005b;20(Suppl.10):S59, P196.
IRLSSG (International Restless Legs Syndrome Study Group). Validation of the International Restless Legs Syndrome Study Group rating scale for restless legs syndrome. Sleep Med. 2003;4:121-132.

Kotagal S, Silber MH. Childhood-onset restless legs syndrome. Ann Neurol. 2004;56:803-807.

Lesage S, Hening WA. The restless legs syndrome and periodic limb movement disorder: a review of management. Semin Neurol. 2004;24:249-259.

Lin, S-C, Kaplan J, Burger CD, Frederickson PA. Effect of pramipexole in treatment of resistant reastless legs syndrome. Mayo Clin Proc. 1998;73:497-500.

Montplaisir J. Restless legs syndrome improved by pramipexole. A double-blind randomized trial. Neurology. 1999;52:938-943.

Montplaisir J, Boucher S, Poirier G, Lavigne G, Lapierre O, Lesperance P. Clinical, polysomnographic, and genetic characteristics of restless legs syndrome: a study of 133 patients diagnosed with new standard criteria. Mov Disord. 1997;14:102-110.

Montplaisir J, Denesle R, Petit D. Pramipexole in the treatment of restless legs syndrome: a follow-up study. Eur J Neurol. 2000;7(Suppl. 1):27-31.

Mytileneou, C, Walker RH, Jonbaptiste R, Olanow CW. Levodopa is toxic to dopamine neurons in an in vitro model, but not in an in vivo model of oxidative stress. J Pharm Exp Ther. 2003;304:792-800.

Oertel W, Stiasny-Kolster K. Pramipexole is effective in the treatment of restless leg syndrome (RLS): results of a six-week, multi-centre, double-blind and placebo-controlled study. Mov Disord. 2005a;20(Suppl. 10):S58, P191

Oertel W, Stiasny-Kolster K. Early and persistent effect of pramipexole in RLS patients already with the starting dose. Mov Disord. 2005b;20(Suppl. 10):S58-59, P194.

Ondo W, Romanyshyn J, Vuong KD, Lai D. Long-term treatment of restless legs syndrome with dopamine agonists. Arch Neurol. 2004;61:1393-1397.

Partinen M, Hirvonen K, Alakuijala A, Jama L, Terttunen J. Rapid relief from RLS symptoms with pramipexole: results of a large polysomnographic study. Poster presented at 56th Annual Meeting of the American Academy of Neurology 2004. Data on file with Boehringer Ingelheim and available as follows:

http://www.boehringeringelheim.com/corporate/news/img/download/Poster_AAN revised.pdf

Prescott LM. Meeting highlights. The 56th Annual Meeting of the American Academy of Neurology. Pharmacy and Therapeutics. 2004;29:453.

Ruottinen HM, Partinen M, Hublin C, Bergman J, Haaparanta M, Solin O, Rinne JO. An FDOPA PET study in patients with periodic limb movement disorder and restless legs syndrome. Neurology. 2000;54:502-504.

Saletu M, Anderer P, Saletu-Zyhlarz G, Hauer C, Saletu, B. Acute placebocontrolled sleep laboratory studies and clinical follow-up with pramipexole in restless legs syndrome. Eur Arch Psychiatr Clin Neurosci. 2002;252:185-194.

Schapira AHV. Restless legs syndrome: an update on treatment options. Drugs. 2004;64:149-158.

Scrip news (2005). GSK gets US approval for Requip in restless legs. www.scripnews.com, May 11th 2005;3053:27.

Silber MH, Girish M, Izurieta R. Pramipexole in the management of restless legs syndrome. Sleep. 2003;26:819-821.

Silber MH, Ehrenberg BL, Allen RP, et al. An algorithm for the management of restless legs syndrome. Mayo Clin Proc. 2004;79:916-922.

Sowers JR, Vlachakis N. Circadian variation in plasma dopamine levels in man. J Endocrinol Invest. 1984;7:341-345.

Stiasny-Kolster K, Oertel, WH. Low-dose pramipexole in the management of restless legs syndrome. Neuropsychobiology. 2004;50:65-70.

Stiasny-Kolster K, Oertel, WH. Pramipexole: an effective treatment option in restless legs syndrome (RLS) patients with depressed mood. Mov Disord. 2005;20(Suppl. 10):S59, P195.

Stiasny-Kolster K, Möller C, Oertel WH. Safety of pramipexole in patients with restless legs syndrome. Neurology. 2000;55:1589-1590.

Stiasny-Kolster K, Magerl W, Oertel WH, Möller JC, Treede R-D. Static mechanical hyperalgesia without dynamic tactile allodynia in patients with restless legs syndrome. Brain. 2004a;127:1-10. 
Stiasny-Kolster K, Möller C, Zschocke J, et al. Normal dopaminergic and serotonergic metabolites in CSF and blood of restless legs syndrome patients. Mov Disord. 2004b;19:192-196.

Stiasny-Kolster K, Trenkwalder C, Fogel W, et al. Restless legs syndrome-new insights into clinical characteristics, pathophysiology, and treatment options. J Neurol. 2004c;251(Suppl. 6):VI/39-VI/43.

Stiasny-Kolster K, Benes H, Peglau I et al. Effective cabergoline treatment in idiopathic restless legs syndrome. Neurology. 2004d;63:2272-2279

Strange PG. Dopamine receptors. Tocris Rev. 2000;15:1-5.

Thorpy M, Ehrenberg BL, Hening WA, et al. Restless legs syndrome. Detection and management in primary care. NIH publication number 00-3788. Bethesda, MD: NIH; 2000: pp. 1-16.
Trenkwalder C, Hundemer HP, Lledo A et al. Efficacy of pergolide in treatment of restless legs syndrome. The PEARLS study. Neurology. 2004;62:1391-1397.

Walters AS, Hening W, Rubinstein M, Chokroverty S. A clinical and polysomnographic comparison of neuroleptic-induced akathisia and the idiopathic restless legs syndrome. Sleep. 1991;14:339-345.

Winkelman JW, Johnston L. Augmentation and tolerance with long-term pramipexole treatment of restless legs syndrome (RLS). Sleep Med. 2004;5:9-14.

Correspondence: William Winlow, Core Medical Publishing, Mere House, Brook Street, Knutsford, Cheshire WA16 8GP, UK or at editor@coreevidence.com 